\title{
Thermostability of cardosin A from Cynara cardunculus L.
}

\author{
David G. Pina $^{\mathrm{a}, 1}$, Claudia S. Oliveira ${ }^{\mathrm{b}, 1}$, Ana C. Sarmento ${ }^{\mathrm{b}}$, Marlene Barros ${ }^{\mathrm{b}, \mathrm{c}}$, \\ Euclides Pires ${ }^{\mathrm{d}}$, Galina G. Zhadan ${ }^{\mathrm{a}}$, Enrique Villar ${ }^{\mathrm{a}}$, Francisco Gavilanes ${ }^{\mathrm{e}}$, \\ Valery L. Shnyrov ${ }^{\mathrm{a}, *}$ \\ ${ }^{a}$ Departamento de Bioquímica y Biología Molecular, Universidad de Salamanca, 37007 Salamanca, Spain \\ ${ }^{\mathrm{b}}$ Departamento de Biologia e Centro de Biologia Celular, Universidade de Aveiro, 3810 Aveiro, Portugal \\ ${ }^{\mathrm{c}}$ Universidade Católica Portuguesa, Centro Regional das Beiras, Pólo de Viseu, 3504-505 Viseu, Portugal \\ ${ }^{\mathrm{d}}$ Departamento de Bioquímica, Faculdade de Ciências e Tecnologia, Universidade de Coimbra, 3000 Coimbra, Portugal

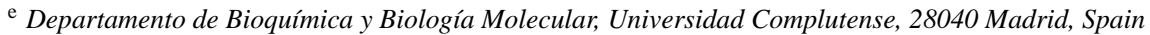

Received 28 August 2002; accepted 18 November 2002

\begin{abstract}
The structural stability of cardosin A, a plant aspartic proteinase (AP) from Cynara cardunculus L., has been investigated by high-sensitivity differential scanning calorimetry, intrinsic fluorescence and circular dichroism spectroscopy, and enzymatic activity assays. Even though the thermal denaturation of cardosin A is partially irreversible, valid thermodynamic data can be obtained within a wide $\mathrm{pH}$ region. Also, although cardosin $\mathrm{A}$ is a heterodimeric enzyme its thermal denaturation occurs without simultaneous dissociation to unfolded monomers. Moreover, in the 3-7 pH region the excess heat capacity can be deconvoluted into two components corresponding to two elementary two-state transitions, suggesting that the two polypeptide chains of cardosin A unfold independently. Detailed thermodynamic and structural investigations of cardosin $\mathrm{A}$ at $\mathrm{pH}=5.0$, at which value the enzyme demonstrates maximum stability and enzymatic activity, revealed that after thermal denaturation the polypeptide chains of this protein retain most of their secondary structure motifs and are not completely hydrated.
\end{abstract}

(c) 2002 Elsevier Science B.V. All rights reserved.

Keywords: Cardosin A; Differential scanning calorimetry; Intrinsic fluorescence; Circular dichroism; Protein stability

\section{Introduction}

Aspartic proteinases (AP) are a class of enzymes (EC 3.4.23) widely distributed within the living world. They are found in vertebrates, fungi, plants and retroviruses and have important roles in biological systems such as precursor protein processing (retroviral proteinases), digestion (pepsin, gastricsin and chymosin),

\footnotetext{
* Corresponding author. Tel.: +34-923-294465; fax: +34-923-294579.

E-mail address: shnyrov@usal.es (V.L. Shnyrov).

1 These authors contributed equally to this work.
}

intracellular protein degradation (cathepsin D), sporulation (fungal proteinases) and blood-pressure regulation (rennin). AP activity has also been correlated with cancer invasiveness and breast and prostate cancer cell proliferation [1,2], the release of $\beta$-amyloid peptides from the amyloid precursor in Alzheimer's disease [3], parasite development (including schistosomes, Plasmodium falciparum and Candida), growth and reproduction in humans [4-6], and HIV virulence [7] among many other examples.

Despite their distribution in retroviruses, bacteria, yeast, fungi, vertebrates, and plants, all AP share significant similarities in their sequences and structures 
as well as regards their general biochemical properties. The members of this class of proteinases display two catalytic Asp-Thr/Ser-Gly motifs within their sequences and are inhibited by pepstatin, a hexapeptide produced by Streptomyces. They also have an acid optimum $\mathrm{pH}$, and preferentially cleave peptide bonds between hydrophobic residues.

Our research focused on a systematic study of cardosin A, an AP present in the pistils of the cardoon, Cynara cardunculus L. (family Asteraceae) [8]. The enzyme is produced as a single-chain zymogen, procardosin A, from which the plant-specific insert and the N-terminal propeptide segment are removed, affording an active two-chain enzyme [9]. Although AP have an acidic optimum $\mathrm{pH}$, along with retroviral proteinases cardosin A shows optimal activity under mild acid conditions, suggesting its sub-cellular localisation.

The refined crystallographic structure of cardosin A displays two peptide chains of 31 and $15 \mathrm{kDa}$, out of a total of 326 amino acids, giving rise a bilobate molecule with two subunits separated by a large cleft where the active site is located [10]. The crystal structure also shows three solvent-exposed loop regions at the end of the flap between residues 75 and 79, and the variable loops 46-47 and 159-160. Three disulphide bridges have been found in the cardosin A mature protein: two within the first peptide chain (Cys45/Cys50 and Cys206/Cys210) (pepsin numbering), and the third within the second peptide chain (Cys249/Cys282), at positions known to form inter-cysteinyl bonds in the AP family [11]. These three covalent bridges do not link the two peptide chains, which must therefore be held together only by hydrophobic interactions and hydrogen bonds arising with the AP fold. In common with other AP, the active site of cardosin A is located between the two lobes of the molecule at the bottom of a large cleft that contains the two catalytic aspartates Asp32 and Asp215.

The sugars are localised on the molecular surface, distributed between two glycosylation sites-Asn67 (in the $31 \mathrm{kDa}$ chain) and Asn257 (in the $15 \mathrm{kDa}$ chain) - away from the conserved active site, and show a new glycan of the plant complex type. A hydrogen bond between Gln126 and Man $\beta 4$ renders the monosaccharide oxygen $\mathrm{O}^{2-}$ sterically inaccessible to accept a xylosyl residue, thereby explaining the new type of the plant glycan identified. In view of their localisation away from the active site [12], the glycans are probably important for the stability and/or correct processing rather than for activity.

The aim of this work was to gain insight into the process of the thermal denaturation of cardosin A. Owing to the potential attractiveness of the use of this enzyme, study of the molecular events taking place in cardosin A upon heating under different solution conditions should be of great academic and practical interest.

\section{Experimental}

HiLoad Superdex 75 prep grade, Q-Sepharose and HiPrep 26/10 desalting columns were from Amersham Pharmacia Biotech (Uppsala, Sweden). Sodium citrate was from Probus, and $\mathrm{HCl}$ and $\mathrm{NaCl}$ were from Panreac (Barcelona, Spain). Tris, MES, HEPES and TAPS were purchased from Sigma (St. Louis, MO, USA). Reagents for electrophoresis were from Bio-Rad Laboratories (Richmond, CA, USA). The Micro BCA ${ }^{\mathrm{TM}}$ protein assay was purchased from Pierce (Cheshire, UK). All reagents were of the highest purity available. Double-distilled water was used throughout.

Cardosin A was purified by a two-step procedure, as previously described [13] with slight modifications. Stigmas from fresh flowers were homogenised with $100 \mathrm{mM}$ sodium citrate, $\mathrm{pH}=3.5$, and centrifuged at $14000 \mathrm{rpm}$ for $10 \mathrm{~min}$. The supernatant was filtered through a $0.2 \mu \mathrm{m}$ filter and applied to a Hiload Superdex 75 prep grade equilibrated and eluted with $25 \mathrm{mM}$ Tris $/ \mathrm{HCl}, \mathrm{pH}=7.6$, at a flow rate of $3 \mathrm{ml} / \mathrm{min}$. The active fraction was further purified on a Q-Sepharose column, equilibrated with the same buffer. The protein was eluted with an optimised gradient of $\mathrm{NaCl}(0.2-1 \mathrm{M})$ at a flow rate of $3 \mathrm{ml} / \mathrm{min}$. All solvents were previously degassed and chromatographic assays were performed at room temperature. Protein peaks were collected and their purity assessed by SDS-PAGE. The enzyme was desalted using a HiPrep 26/10 desalting column and then concentrated by means of lyophilization after freezing with liquid nitrogen on a Dura-Dry ${ }^{\mathrm{TM}}$ apparatus at a condensator temperature of $-50^{\circ} \mathrm{C}$ and a pressure lower than 100 mTorr.

Sample purity was checked by SDS/PAGE and by isoelectrofocusing. Electrophoresis was performed 
as described by Fairbanks et al. [14] on a Bio-Rad minigel apparatus using a flat block with a polyacrylamide gradient of 5-25\%. Gels were prefixed and stained using the method of Merril et al. [15]. Analytical isoelectrofocusing performed using Ampholine PAGE plates (Amersham-Pharmacia), with a $\mathrm{pH}$ range 3-10. Electrophoretic conditions and silver staining were carried out as recommended by the manufacturer. The standards used were the broad $\mathrm{p} I$ calibration kit ( $\mathrm{pH}=3-10$ ) from Amersham-Pharmacia.

Protein concentration was determined spectrophotometrically at $280 \mathrm{~nm}$, using an extinction coefficient of $43.8 \times 10^{3} \mathrm{M}^{-1} \mathrm{~cm}^{-1}$ based on a $46 \mathrm{kDa}$ molecular weight for the cardosine A dimer [16].

The calorimetric experiments were performed on a MicroCal MC-2D differential scanning microcalorimeter (MicroCal Inc., Northampton, MA) with cell volumes of $1.22 \mathrm{ml}$, as described previously [17]. The calorimetric unit was interfaced with an IBM-compatible computer for automatic data collection and analysis. The sample and the reference solutions were properly degassed in an evacuated chamber at room temperature and carefully loaded into the calorimeter to eliminate bubbling effects. An overpressure of $2 \mathrm{~atm}$ of dry nitrogen was kept over the liquids in the cells to prevent any degassing during heating. A scanning rate of $60 \mathrm{~K} / \mathrm{h}$ was employed throughout, since no significant scan rate effect was observable. The baseline was obtained with buffer in both reference and sample cells. To test for the ability of the protein to become denatured, the sample was cooled at the end of the first scan, allowed to re-equilibrate to the starting temperature, and then scanned again. The percentage of denaturation is expressed as the calorimetric enthalpy change $\left(\Delta H_{\text {cal }}\right)$ of the second scan divided by that of the first one. The excess heat capacity function was analysed after normalisation and baseline subtraction using ORIGIN software package supplied by MicroCal.

Steady-state fluorescence measurements were carried out on a F-4010 Hitachi spectrofluorimeter. The intrinsic fluorescence of the proteins arises from the aromatic amino acid residues. Here we used the fluorescence of tryptophan residues available in the enzyme. A fluorescence excitation wavelength of $295 \mathrm{~nm}$ was used to avoid the contribution of the emission of residues other than tryptophan. The monochromator slit width was kept at $5 \mathrm{~nm}$ in the excitation and emission channels. Fluorescence was measured in the range $300-400 \mathrm{~nm}$. The fluorescence measurements of the enzyme were carried out on protein solutions with an optical density of less than 0.2 at $295 \mathrm{~nm}$ to avoid the inner filter effect. The emission spectra were corrected for instrumental spectral sensitivity. The position of the middle of a chord drawn at the $80 \%$ level of maximum intensity $\left(\lambda_{\max }\right)$ was taken as the position of the spectrum. The temperature-dependence of the emission fluorescence spectra was investigated using thermostatically controlled water circulating in a hollow brass cell-holder. The temperature of the sample was monitored with a thermocouple immersed in the cell under observation. The heating rate was between 0.6 and $1.2 \mathrm{~K} / \mathrm{min}$, and spectra were collected at the desired temperatures over the entire temperature range. In titration experiments, $\mathrm{pH}$ values were adjusted by means of a polyethylene rod moistened with either $0.1 \mathrm{M} \mathrm{HCl}$ or $0.1 \mathrm{M} \mathrm{NaOH}$. The fluorescence spectra were analysed on the basis of the model of discrete states of tryptophan in proteins [18-20].

The far-UV CD spectra $(195-250 \mathrm{~nm})$ of cardosin A were recorded on a Jasco-715 spectropolarimeter, using a spectral band-pass of $2 \mathrm{~nm}$ and a cell path-length of $1 \mathrm{~mm}$. Protein concentrations of $0.1-0.2 \mathrm{mg} / \mathrm{ml}$ were used in these measurements. Four spectra were scanned for each sample at a scan rate of $50 \mathrm{~nm} / \mathrm{min}$ and were then averaged. All spectra were background-corrected, smoothed and converted to mean residue ellipticity $[\Theta]=10 M_{\text {res }} \Theta_{\text {obs }} l^{-1} p^{-1}$, where $M_{\text {res }}$ is the mean residue molar mass (protein molecular mass divided by the number of amino acid residues), $\Theta_{\text {obs }}$ the ellipticity $\left(^{\circ}\right)$ measured at wavelength $\lambda, l$ the optical path-length of the cell $(\mathrm{dm})$ and $p$ the protein concentration $(\mathrm{mg} / \mathrm{ml})$. Secondary structure analysis of CD spectra was performed using the SELCON3 software package [21]. To study the dependence of ellipticity on temperature, the samples were heated from 283 to $363 \mathrm{~K}$ at a constant heating rate (ca. $1 \mathrm{~K} / \mathrm{min}$ ) using a NESLab RT-11 programmable water bath.

The proteolytic activity of cardosin A was assayed using the chromogenic synthetic peptide LysPro-Ala-Glu-Phe-Phe $\left(\mathrm{NO}_{2}\right)$-Ala-Leu (courtesy of Dr. Arthur J.G. Moir) as substrate. Enzyme preparations were incubated at desired temperature with $0.242 \mathrm{mM}$ substrate in $50 \mathrm{mM}$ sodium acetate with $0.2 \mathrm{M} \mathrm{NaCl}$ and $4 \%(\mathrm{Me})_{2} \mathrm{SO}, \mathrm{pH}=4.7$. The rate 
of hydrolysis of Phe-Phe $\left(\mathrm{NO}_{2}\right)$ was monitored by RP-HPLC [16].

\section{Results and discussion}

The thermal stability of cardosin A was studied using high-sensitivity differential scanning calorimetry. Fig. 1 shows the temperature-dependence of the partial molar heat capacity of cardosin $\mathrm{A}$ at a concentration of $30 \mu \mathrm{M}$ in $20 \mathrm{mM}$ HEPES, $\mathrm{pH}=7.0$. Under the conditions of this experiment, the thermal denaturation transition of cardosin A occurs at $332.9 \mathrm{~K}$ and is characterised by an enthalpy change of $728 \mathrm{~kJ} / \mathrm{mol}$ and a change in heat capacity $\left(\Delta C_{p}\right)$ of $17.2 \mathrm{~kJ} \mathrm{~K}^{-1} \mathrm{~mol}^{-1}$. At $25^{\circ} \mathrm{C}$, the heat capacity of the native state is $49.8 \mathrm{~kJ} \mathrm{~K}^{-1} \mathrm{~mol}^{-1}$ or $1.42 \mathrm{~J} \mathrm{~K}^{-1} \mathrm{~g}^{-1}$, comparable to the values reported for other proteins [22,23]. Fig. 1 also shows that the heat capacity of native cardosin A observed here is in good agreement with the values calculated using a structure-based parameterisation [23]. Also, the heat capacity of the denatured state is lower than that expected for an unstructured polypeptide of the same amino acid composition, suggesting that even in this state the polypeptide chain retains a residual structure and is not completely hydrated after thermal denaturation.

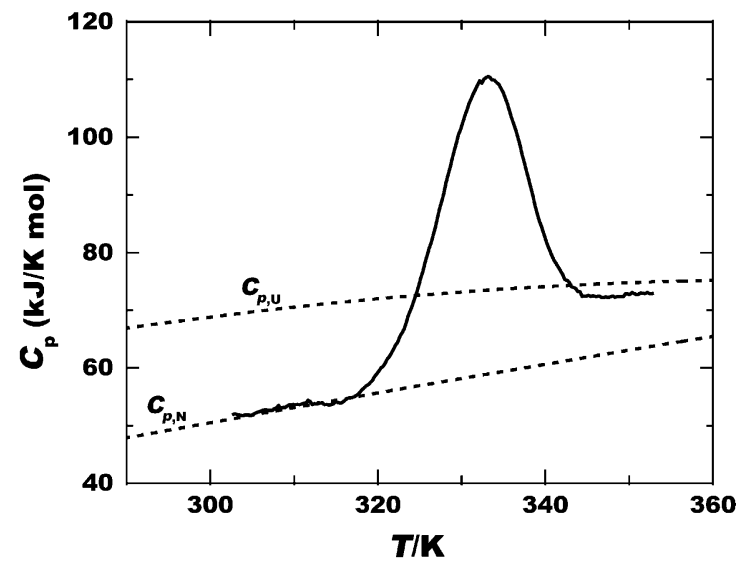

Fig. 1. Partial molar heat capacity of cardosin A as a function of temperature at $\mathrm{pH}=7.0$ (20 mM HEPES buffer). The experiment was performed at a scan rate of $60 \mathrm{~K} / \mathrm{h}$ and the protein concentration was $30 \mu \mathrm{M}$. The dashed lines represent the heat capacities of the native, $C_{p \mathrm{~N}}$, and unfolded, $C_{p \mathrm{U}}$, states, respectively, calculated using a structure-based parameterisation [23].
It should be noted here that the specific enthalpy change of $16.15 \mathrm{~J} / \mathrm{g}$ is also indicative of the lack of complete unfolding of cardosin A upon heat denaturation because this value is significantly lower than the value observed for most globular proteins at the same temperature [22].

It is well known that a correct thermodynamic description of protein stability is possible only if its experimentally measured unfolding transition is reversible. The extent of reversibility, measured by relative area recovery, seen on the second scan of cardosin A depended on the temperature at which the first scan was terminated before cooling the samples in preparation for the second scan. When the first scan was allowed to proceed up to a temperature at which the transition was $50 \%$ complete, then the repeated scans showed approximately $85 \%$ reversibility. However, heating up to temperatures at which the transition was $90 \%$ complete reduced reversibility by up to $30 \%$. When the first scan progressed up to higher temperatures, the transition became completely irreversible. We found, however, that the DSC scans measured for cardosin A were practically independent of the scan rate. Experiments performed at scanning rates of 28,60 and $89 \mathrm{~K} / \mathrm{h}$ gave similar denaturation profiles that differed in the transition temperatures $\left(T_{\mathrm{m}}\right)$ by less than $0.3 \mathrm{~K}$, indicating the absence of kinetic effects under our experimental conditions. We therefore concluded that the data could still be analysed semi-quantitatively using thermodynamic models [24-26].

According to equilibrium thermodynamics, any change in the oligomerization state of proteins during their thermal denaturation should produce a concentration-dependence of $T_{\mathrm{m}}$ [27]. The absence of such dependence may therefore be taken as evidence that the denatured protein remains in the same oligomerization state as the native protein [28]. Since cardosin A is a hetero-dimeric protein, we investigated the dependence of its thermal transition temperature on the protein concentration. It turned out that the thermal transition temperature of cardosin A does not depend on the protein concentration (differed by less than $0.4 \mathrm{~K}$ ) within the $6.5-105 \mu \mathrm{M}$ (ca. $0.3-4.8 \mathrm{mg} / \mathrm{ml}$ ) range, i.e. thermal denaturation of cardosin $\mathrm{A}$ is not accompanied by simultaneous dissociation of the folded dimer to the unfolded monomers. This unusual situation for multimeric proteins can be explained in terms 
of the idea that the thermal denaturation of cardosin A would occur without its complete unfolding and, in particular, that some structural elements responsible for the interaction between the two different cardosin A chains would remain. This suggestion finds experimental support in that the value of the specific enthalpy change for cardosin A is almost twofold lower than the value observed for most globular proteins at the same denaturation temperature (see above), and also, as may be seen from the data offered below, that a considerable portion of the secondary and tertiary structure elements in the denatured state of cardosin A persists.

Fig. 2 shows a set of the excess heat capacity functions for cardosin A (solid lines) at different $\mathrm{pH}$ values obtained after correction of the experimental traces for the instrumental baseline and the chemical baseline in accordance with [29]. It is important to note here that none of the DSC curves shown in this figure displayed the typical asymmetry that would be expected if denaturation were to take the form $\mathrm{N}_{m} \rightarrow m \mathrm{U}$, where $\mathrm{N}$ and $U$ represent the native and denatured protein, respectively, the protein remaining oligomeric up to the denaturation temperature and then undergoing simultaneous denaturation and dissociation to $m$ molecules of the unfolded protein [30]. Moreover, for the calorimetric profiles obtained the ratio of the van't Hoff enthalpy [defined using the familiar formula $\Delta H_{\mathrm{VH}}=$ $\left.4 R T_{\mathrm{m}}^{2} C_{p}^{\max } / \Delta H\left(T_{\mathrm{m}}\right)\right]$ and the calorimetric enthalpy $\left[\Delta H_{\mathrm{VH}} / \Delta H\left(T_{\mathrm{m}}\right)\right]$ averaged $0.45 \pm 0.04$ for $\mathrm{pH}$ values of $3,4,5,6,7$ and 8 and $1.08 \pm 0.05$ for $\mathrm{pH}$ value of 9 . The value of 0.45 is close to 0.5 , which would be found for two-state transition of a dimeric protein [31], while the value of 1.08 is close to 1 , which would be found for two-state transition of monomeric protein [32]. The results of the deconvolution of the DSC profiles obtained by means of the Microcal software under the assumption of an independent two-state model of unfolding (dashed lines) are shown in Fig. 2 and Table 1. It is clearly seen that the model offers a good description of cardosin A thermal unfolding at different $\mathrm{pH}$ values.

The two-chain structure of cardosin A strongly implies that this scheme reflects the independent unfolding of its two chains. Since the chains are of different size but similarly folded [10], they are expected to have different unfolding enthalpies, which really is the case. We assigned the minor and major peaks to the

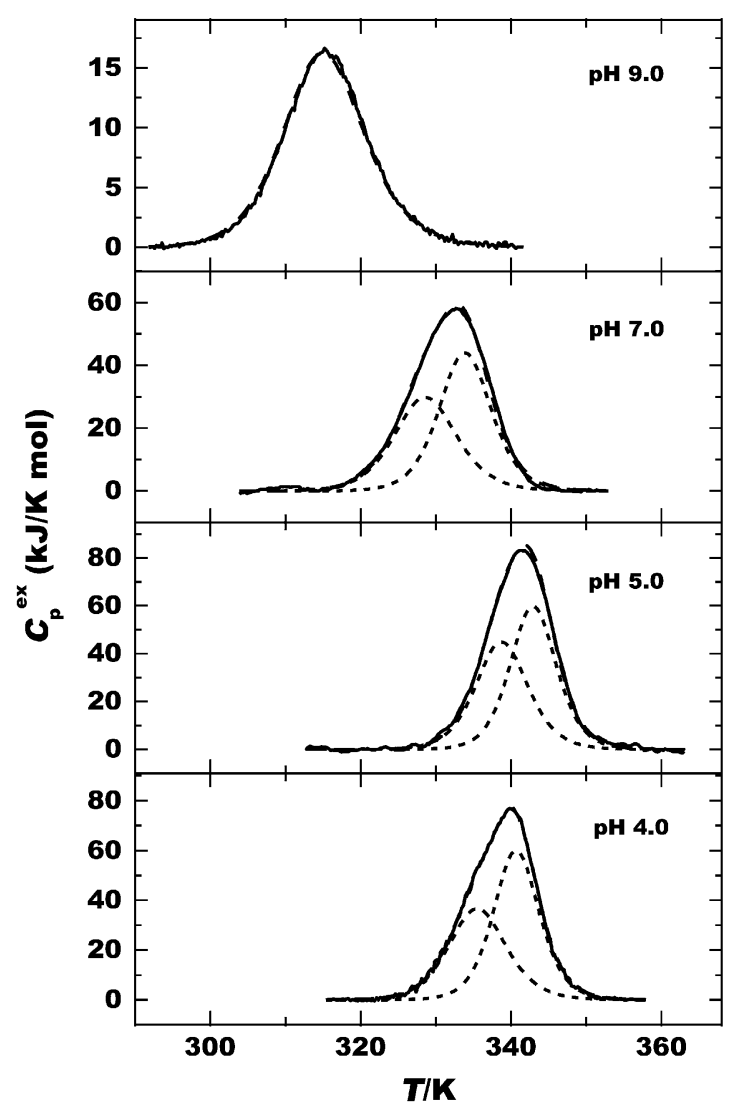

Fig. 2. Temperature-dependence of the excess molar heat capacity of cardosin $\mathrm{A}$ at the different $\mathrm{pH}$ indicated in the figure after correction of the experimental traces for the chemical baseline in accordance with [29]. Dashed lines represent the results of non-linear least-squares fittings of experimental curves to the two-state independent model as implemented in the Origin software package. Protein concentration was $30 \mu \mathrm{M}$.

unfolding of the shorter and longer chain, respectively, and designated their enthalpies as $\Delta H_{\mathrm{S}}, \Delta H_{\mathrm{L}}$ and the transition temperatures as $T_{\mathrm{mS}}, T_{\mathrm{mL}}$, where the subscripts $\mathrm{S}$ and $\mathrm{L}$ stand for the shorter and longer chains. As follows from an analysis of the DSC scans, the $T_{\mathrm{m}}$ for both chains of cardosin A remains essentially the same within the $\mathrm{pH}$ region from 4.0 to 6.0 , whereas it decreases substantially at $\mathrm{pH}$ values below 3.0 and above 7.0. In the $\mathrm{pH}$ region where the protein is relatively reversible, the change in calorimetric enthalpy is linearly related to $T_{\mathrm{m}}$ (Fig. 3). The linear relationship between $\Delta H_{\text {cal }}$ and $T_{\mathrm{m}}(r=0.99)$ in the $\mathrm{pH}$ region from 3.0 to 9.0 provides a unique way to estimate $\Delta C_{p}$ values for both cardosin A chains separately, since the 
Table 1

Thermodynamic parameters for the individual transitions of cardosin A obtained by differential scanning calorimetry at different $\mathrm{pH}$ values $\mathrm{s}^{\mathrm{a}}$

\begin{tabular}{|c|c|c|c|c|c|c|c|c|c|c|c|c|}
\hline \multirow[t]{2}{*}{$\mathrm{pH}$} & \multicolumn{6}{|c|}{ First transition } & \multicolumn{6}{|c|}{ Second transition } \\
\hline & $T_{\mathrm{m}}(\mathrm{K})$ & $\begin{array}{l}\Delta H\left(T_{\mathrm{m}}\right) \\
(\mathrm{kJ} / \mathrm{mol})\end{array}$ & $\begin{array}{l}\Delta C_{p} \\
(\mathrm{~kJ} / \mathrm{K} \mathrm{mol})\end{array}$ & $\begin{array}{l}\Delta G^{\circ}(298 \mathrm{~K}) \\
(\mathrm{kJ} / \mathrm{mol})\end{array}$ & $T_{\mathrm{S}}(\mathrm{K})$ & $\begin{array}{l}\Delta G^{\circ}\left(T_{\mathrm{s}}\right) \\
(\mathrm{kJ} / \mathrm{mol})\end{array}$ & $T_{\mathrm{m}}(\mathrm{K})$ & $\begin{array}{l}\Delta H\left(T_{\mathrm{m}}\right) \\
(\mathrm{kJ} / \mathrm{mol})\end{array}$ & $\begin{array}{l}\Delta C_{p} \\
(\mathrm{~kJ} / \mathrm{K} \mathrm{mol})\end{array}$ & $\begin{array}{l}\Delta G^{\circ}(298 \mathrm{~K}) \\
(\mathrm{kJ} / \mathrm{mol})\end{array}$ & $T_{\mathrm{s}}(\mathrm{K})$ & $\begin{array}{l}\Delta G^{\circ}\left(T_{\mathrm{s}}\right) \\
(\mathrm{kJ} / \mathrm{mol})\end{array}$ \\
\hline 3.0 & 329.8 & 334.7 & 10.0 & 16.4 & 298.1 & 16.4 & 336.4 & 431.0 & 8.8 & 29.1 & 290.8 & 30.0 \\
\hline 4.0 & 335.6 & 370.3 & & 19.5 & 300.7 & 19.6 & 340.7 & 477.0 & & 35.2 & 290.5 & 36.1 \\
\hline 5.0 & 338.8 & 413.8 & & 24.1 & 300.0 & 24.2 & 342.9 & 485.3 & & 36.5 & 291.9 & 37.1 \\
\hline 6.0 & 335.9 & 380.3 & & 20.6 & 300.1 & 20.7 & 340.8 & 447.7 & & 31.6 & 293.5 & 31.8 \\
\hline 7.0 & 328.8 & 318.4 & & 14.9 & 298.4 & 14.9 & 333.9 & 403.8 & & 25.8 & 291.0 & 26.6 \\
\hline 8.0 & 319.2 & 212.1 & & 6.9 & 298.7 & 6.9 & 328.0 & 350.6 & & 19.5 & 290.4 & 20.5 \\
\hline 9.0 & - & - & & - & - & - & 315.1 & 235.6 & & 8.8 & 289.4 & 9.8 \\
\hline
\end{tabular}

${ }^{\mathrm{a}} T_{\mathrm{m}}$ is defined as the temperature at the midpoint of the unfolding transition (the standard deviation is $\pm 0.2 \mathrm{~K}$ ); $\Delta H\left(T_{\mathrm{m}}\right)$ is the calorimetric enthalpy of the unfolding transition with a standard deviation of $\pm 5 \% ; \Delta C_{p}$ is the difference between the heat capacities of the intact and denatured states obtained from the slope of the graph of the temperature-dependence of $\Delta H\left(T_{\mathrm{m}}\right)$ by $\mathrm{pH}$ variation of $T_{\mathrm{m}}$ (the standard deviations are $\pm 0.4 \mathrm{~kJ} / \mathrm{K}$ mol); the free energy changes, $\Delta G^{\circ}$, were calculated with the Gibbs-Helmholtz equation (2); temperature of maximum stability, $T_{\mathrm{s}}$, was calculated with Eq. (3). 


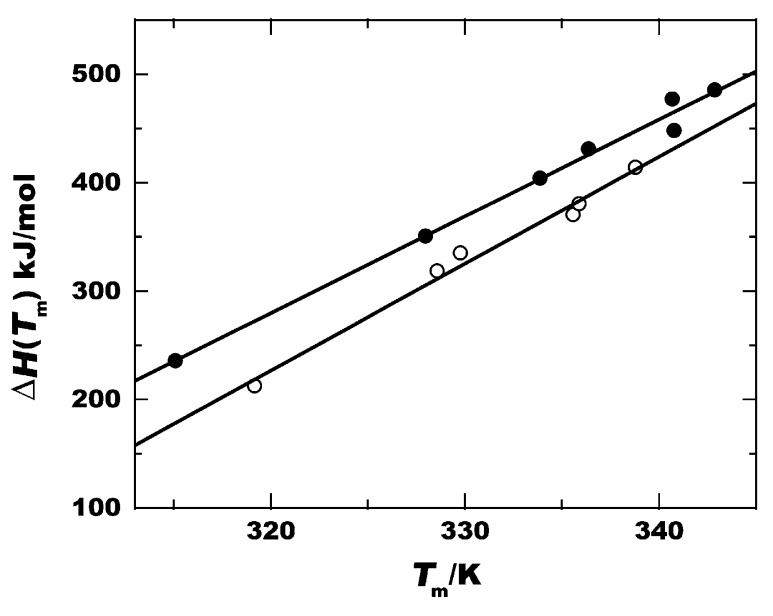

Fig. 3. Linear least-squares determination of the apparent relative heat capacity of the denatured states of cardosin A subunits, $\Delta C_{p}$. The $T_{\mathrm{m}}$ and $\Delta H$ values for the long (solid circles) and short (open circles) chains of cardosin A were obtained by fitting the DSC traces measured at seven $\mathrm{pH}$ values to an independent two-state model.

marked overlapping of the transitions in cardosin A precludes even rough estimates of $\Delta C_{p}$ for each chain from the total calorimetric scan. The changes in heat capacity upon unfolding determined from the slopes of the straight lines are $\Delta C_{p \mathrm{~S}}=10.0 \pm 0.4 \mathrm{~kJ} / \mathrm{K} \mathrm{mol}$ and $\Delta C_{p \mathrm{~L}}=8.8 \pm 0.4 \mathrm{~kJ} / \mathrm{K}$ mol for the shorter and longer chains, respectively.
The pH-dependent behaviour of cardosin A was examined not only by DSC but also by circular dichroism and intrinsic fluorescence spectroscopy and enzymatic assays. Cardosin $\mathrm{A}$ is active at $\mathrm{pH}$ from 2.5 to 7.5 , maximum activity being seen at around $\mathrm{pH}=5.0$ (Fig. 4). The same figure depicts the $\mathrm{pH}$-dependence of the position of the tryptophan fluorescence spectrum position and the ellipticity at $205 \mathrm{~nm}$ of cardosin A measured at $293 \mathrm{~K}$. In the $\mathrm{pH}$ range from 2 to 7 , both the spectral position and ellipticity at $205 \mathrm{~nm}$ remain constant. The red shift of the fluorescence spectrum and the increase in the negative value of ellipticity at $205 \mathrm{~nm}$ at $\mathrm{pH}$ below 2.0 seem to be caused by protonation of some of the carboxyl groups of the enzyme. At $\mathrm{pH}$ above 8 we observed a two-step red shift in the fluorescence spectrum and changes in ellipticity at $205 \mathrm{~nm}$ that could be due to alkaline denaturation of the cardosin A chains triggered by deprotonation of Cys 249 or/and Cys282 (pK about 8.5) for the short chain and some Tyr or/and Lys residues ( $\mathrm{p} K$ about 10) for the long chain. The fact that the short chain of cardosin A is denatured at $\mathrm{pH}$ values above 8 was confirmed by the calorimetric results. The molar heat capacity curve for cardosin $\mathrm{A}$ at $\mathrm{pH}=9.0$ can only be approximated by a single elementary contour under the assumption of a two-state model of unfolding and the parameters of this transition correspond to the linear relationship between $\Delta H_{\text {cal }}$ and $T_{\mathrm{m}}$ only for the long cardosin A

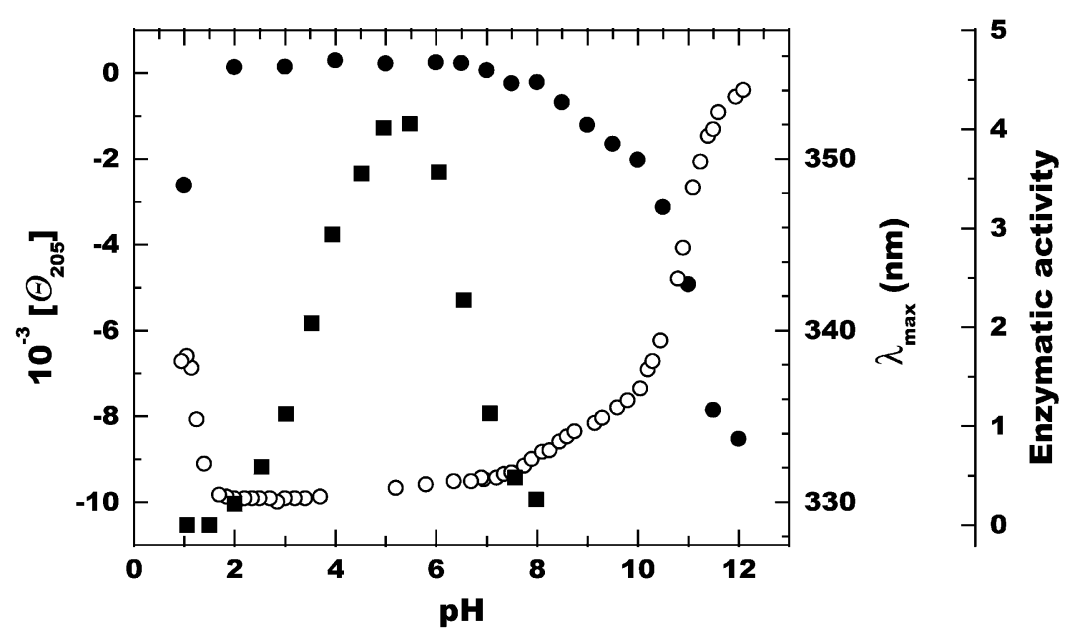

Fig. 4. Variation with $\mathrm{pH}$ of the fluorescence spectrum position (open circles), ellipticity at $205 \mathrm{~nm}$ (closed circles), and enzymatic activity (closed squares) for cardosin $\mathrm{A}$ at $298 \mathrm{~K}$. 


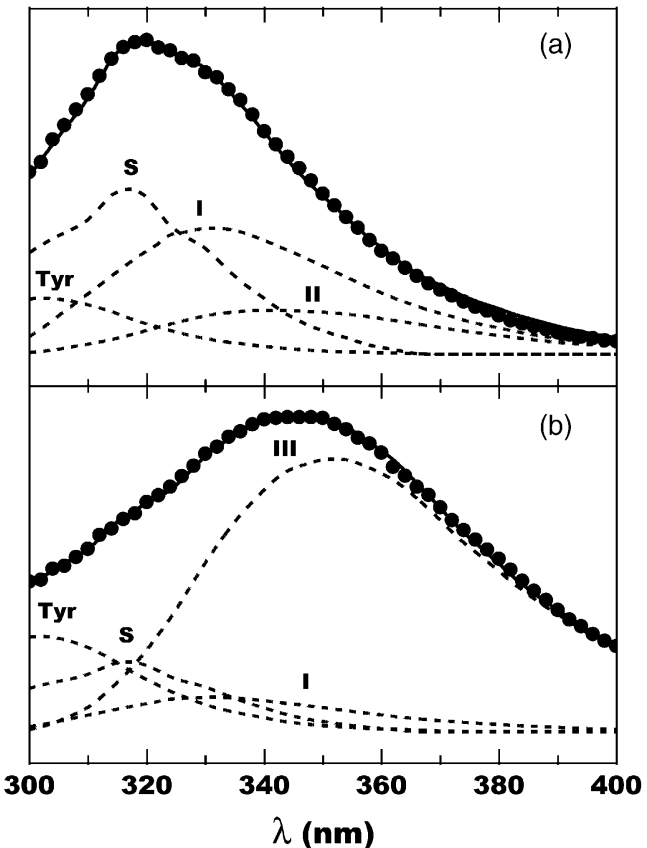

Fig. 5. Fitting of the experimental fluorescence spectra of intact (a) and thermally denatured at $358 \mathrm{~K}$ (b) cardosin A (symbols) to the theoretical model of discrete states of tryptophan residues in proteins [18-20] (solid lines), which are the sums of the spectral components Tyr, S, I, II and III (dashed lines).

chain. Taking into account the results of $\mathrm{pH}$ titration of cardosin A, all further studies on thermal stability of the protein were carried out at $\mathrm{pH}=5.0$, the value at which the enzyme shows maximum activity.

Changes in the environment of aromatic amino acid side chains resulting from conformational changes in the tertiary structure of proteins can be measured by intrinsic fluorescence spectroscopy. Fig. 5 (symbols) shows the emission spectra of intact (a) and thermally denatured at $358 \mathrm{~K}$ (b) cardosin $\mathrm{A}$ at $\mathrm{pH}=5.0$, excited at $295 \mathrm{~nm}$. It is clearly seen from the figure that thermal denaturation of the protein results in a red shift of the tryptophan fluorescence spectrum maximum by more than $20 \mathrm{~nm}$, from 323 to $347 \mathrm{~nm}$ (which is close to the spectrum position of free tryptophan in water), which means that polar tryptophan environment becomes more mobile upon thermal unfolding. This usually occurs when tryptophan residues move from the hydrophobic interior to the protein surface in contact with free water molecules. The most interesting feature of the spectrum of intact cardosin A (Fig. 5a) is the occurrence of elements with a fine vibrational structure: a maximum at $319 \mathrm{~nm}$ and a shoulder at $330 \mathrm{~nm}$. This shows that part of the tryptophan residues in this protein is located in a mostly non-polar, rigid environment. Analysis of the spectrum in terms of the model of discrete states of tryptophan residues in proteins [18-20] shows that the tryptophan residues of the $S$ and I forms (internal tryptophan residues forming two different types of exiplexes with polar groups) provide the main contributions to the emission. Thermal denaturation of the protein results in a pronounced red shift of the tryptophan fluorescence spectrum (Fig. 5b). Tryptophan residues of the form III (external tryptophan residues in contact with free water molecules) provide the main contribution to the emission in this state. Nevertheless, even in this state part of the tryptophan residues is located inside the protein structure (forms $\mathrm{S}$ and $\mathrm{I}$ ).

Fig. 6a depicts the temperature-dependence of normalised fluorescence intensity (solid symbols) recorded at a heating rate of ca. $0.5 \mathrm{~K} / \mathrm{min}$ and the first-order temperature derivatives of these data (open symbols) at $\mathrm{pH}=5.0$. Taking into account the complicated denaturation mechanism obtained following analysis of the DSC data, we analysed the first-order temperature derivative of the fluorescence experimental data (open symbols in Fig. 6a), assuming a superposition of two independent transitions, from each of which a two-state reversible equilibrium process between native and denatured states follows. The best global fit of these data (solid line) was achieved accepting that the parameters of these assumed contours satisfy the equation:

$\Delta H\left(T_{\mathrm{m}}\right)=\frac{4 R T_{\mathrm{m}}^{2}}{\Delta T}$

( $\Delta T$ is the width at the half-height of the contour [32]) with $\Delta T$ values taken from the analysis of calorimetric profiles (Fig. 2). The means of the enthalpy of the denaturation and transition temperatures for the short and long chains of cardosin $\mathrm{A}$ are $\Delta H_{\mathrm{S}}=$ $377.4 \pm 17.2 \mathrm{~kJ} / \mathrm{mol}, \Delta H_{\mathrm{L}}=496.2 \pm 25.1 \mathrm{~kJ} / \mathrm{mol}$, $T_{\mathrm{mS}}=339.3 \pm 2.1 \mathrm{~K}$ and $T_{\mathrm{mL}}=342.7 \pm 1.5 \mathrm{~K}$, in sufficiently good agreement with the calorimetric results.

It is important to note here that the process of fluorescence intensity change with temperature is accompanied by an increase in the aggregation (not dissociation) of cardosin molecules at temperatures 


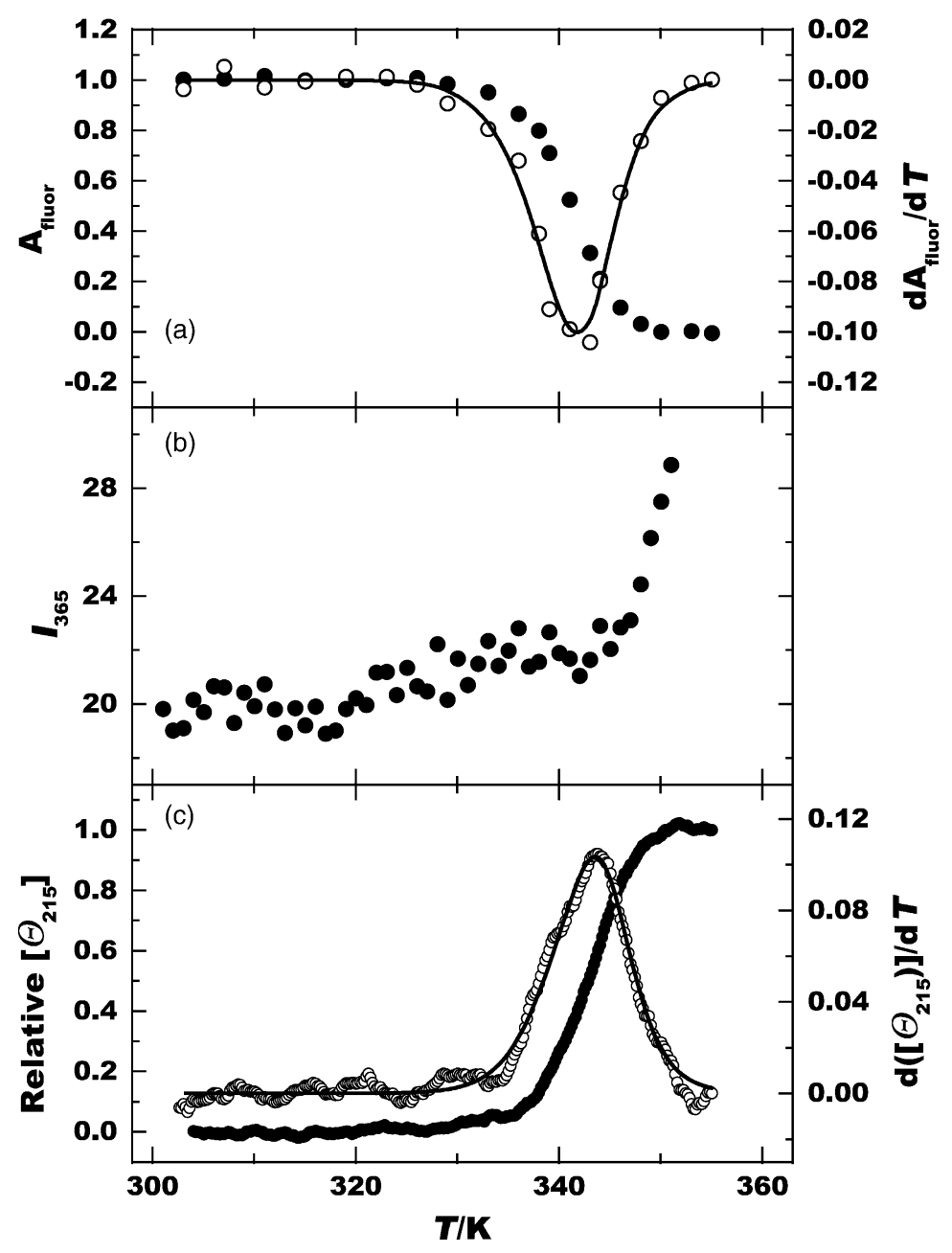

Fig. 6. Thermal denaturation profiles (closed symbols) of cardosin $\mathrm{A}$ at $\mathrm{pH}=5.0$, monitored by measuring the normalised area under the fluorescence spectrum (a) and followed by the ratio between ellipticity at $215 \mathrm{~nm}$ at the indicated temperature and ellipticity at $298 \mathrm{~K}$ (c). The open symbols in these figures are first-order temperature derivatives of the corresponding experimental data and the solid lines are the results of fitting the data assuming a two-state unfolding model. The relative intensity of scattered light at $365 \mathrm{~nm}$ is shown in (b).

above $343 \mathrm{~K}$ as reflected in the increase in scattered light intensity (Fig. 6b).

The CD spectra of intact and thermally denatured cardosin $\mathrm{A}$ at $\mathrm{pH}=5.0$ are shown in Fig. 7. The spectrum of intact cardosin $\mathrm{A}$ (solid line) at $\mathrm{pH}=5.0$ displays a broad minimum at $217 \mathrm{~nm}$, which is characteristic of $\beta$-structure-rich proteins. The spectrum of intact enzyme was not sensitive to protein concentrations ranging from 0.05 to $1 \mathrm{mg} / \mathrm{ml}$. Profound changes in the CD spectra take place after the thermal denaturation of cardosin A, clearly indicating a change in structure: the broad band centred at $217 \mathrm{~nm}$ decreases in intensity and changes in shape while the positive band at $197 \mathrm{~nm}$ is transformed into a negative band at $200 \mathrm{~nm}$.

The content of secondary structure elements obtained by analysis of intact and thermally denatured cardosin A CD spectra following the SELCON3 selfconsistent method [21] is given in Table 2. The contents in $\alpha$-helix (7\%), $\beta$-strand $(43 \%)$ and $\beta$-turn $(20 \%)$ are in reasonably good agreement with the atomic structure of cardosin $\mathrm{A}$, which shows the presence 


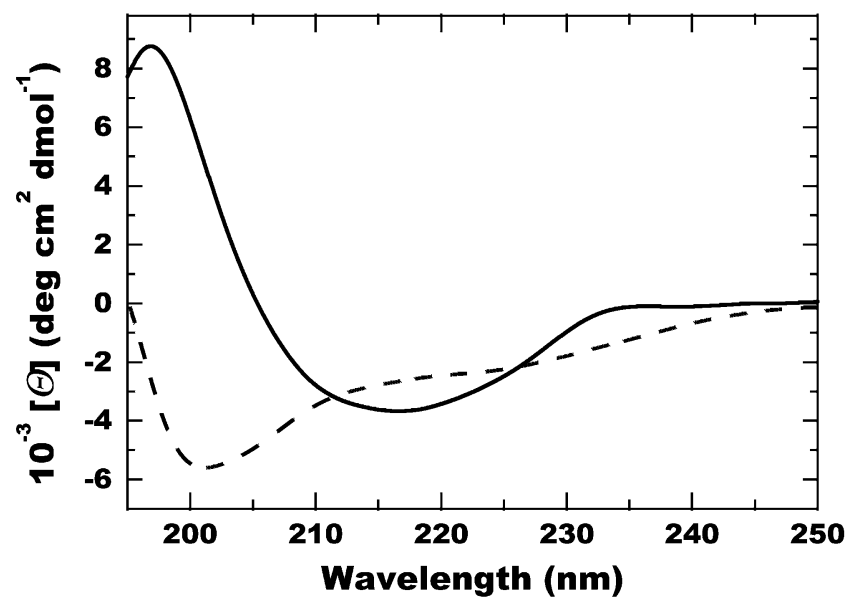

Fig. 7. Far ultraviolet $\mathrm{CD}$ of intact cardosin $\mathrm{A}$ at $298 \mathrm{~K}$ (solid line) and thermally denatured at $358 \mathrm{~K}$ (dashed line) at $\mathrm{pH}=5.0$.

of $10 \%$ of $\alpha$-helices, $35 \%$ of $\beta$-strands and $30 \%$ of $\beta$-turns [10]. The number of $\alpha$-helical and $\beta$-strand segments and their average length estimated from the analysis of the CD spectra for intact cardosin A (see Table 2) also agree fairly well with the crystal structure data, which show the availability of six $\alpha$-helical segments, with an average length of 5.5 residues, and of $24 \beta$-strand segments, with an average length of five residues. Analysis of the CD spectrum of denatured cardosin A reveals that many of the secondary structure elements of this enzyme persist even in this state (see Table 2). The thermal denaturation leads to the almost complete disappearance of $\beta$-turns and an increase in unordered structure, while the contents in $\alpha$-helical and $\beta$-strand structures remain unchanged. The number of $\alpha$-helical segments and their average lengths also remain the same as in intact cardosin A, while the number of $\beta$-strand segments is reduced by six segments, with an increase in the average length of these segments of ca. 2 residues. Once again, these data confirm the notion that cardosin A does not undergo complete unfolding upon heat denaturation.

The process of thermal denaturation of cardosin A at $\mathrm{pH}=5.0$ was monitored by changes in molar ellipticity at $215 \mathrm{~nm}$, since at this wavelength both the pre-transitional and post-transitional baselines show only a weak temperature-dependence. Fig. 6c (closed symbols) shows the normalised thermal denaturation curve of cardosin $\mathrm{A}$ at $\mathrm{pH}=5.0$ upon heating from 303 to $358 \mathrm{~K}$ as measured by $\mathrm{CD}$. The reversibility of the thermal denaturation of this enzyme was verified by superimposing the transition curves recorded at different heating rates from 0.6 to $2 \mathrm{~K} / \mathrm{min}$, and by restoring the $\mathrm{CD}$ spectra upon heating to $333 \mathrm{~K}$, followed by re-equilibration at $298 \mathrm{~K}$. The result of this verification was similar to the results obtained in the calorimetric investigations, demonstrating approximately $80 \%$ reversibility.

Table 2

Secondary structure elements predicted from analysis of $\mathrm{CD}$ spectra for intact and thermally denatured cardosin $\mathrm{A}$ at $\mathrm{pH}=5.0^{\mathrm{a}}$

\begin{tabular}{|c|c|c|c|c|c|c|c|c|c|c|c|c|}
\hline \multirow[t]{3}{*}{ Protein } & \multicolumn{8}{|c|}{ Secondary structure fractions $(\%)$} & \multicolumn{2}{|c|}{$\alpha$-Helical segments } & \multicolumn{2}{|c|}{$\beta$-Strand segments } \\
\hline & \multicolumn{3}{|c|}{$\alpha$-Helices } & \multicolumn{3}{|c|}{$\beta$-Strands } & \multirow[t]{2}{*}{$\beta$-Turns } & \multirow[t]{2}{*}{ Unordered } & \multirow[t]{2}{*}{$N_{\alpha}$} & \multirow[t]{2}{*}{$L_{\alpha}$} & \multirow[t]{2}{*}{$N_{\beta}$} & \multirow[t]{2}{*}{$L_{\beta}$} \\
\hline & Regular & Distorted & Total & Regular & Distorted & Total & & & & & & \\
\hline Intact & 1.9 & 5.1 & 7.0 & 28.2 & 14.7 & 42.9 & 20.2 & 29.9 & 4 & 5.1 & 25 & 5.8 \\
\hline Denatured & 1.2 & 5.6 & 6.8 & 31.6 & 12.6 & 44.2 & 1.0 & 48.0 & 4 & 4.8 & 19 & 7.6 \\
\hline
\end{tabular}

\footnotetext{
${ }^{a}$ The number $(N)$ and average length $(L)$ of $\alpha$-helix $(\alpha)$ and $\beta$-strand $(\beta)$ are given.
} 
The first-order temperature derivative of the unfolding curve (open symbols in Fig. 6c) was analysed assuming that it consists of two components (solid line), in the same way as in the case of the analysis of the fluorescence data. The means for the enthalpy of the denaturation and transition temperatures for the short and long chains of cardosin A obtained from the best global fit (see above) of this curve (solid line) $-\Delta H_{\mathrm{S}}=391.2 \pm 15.9 \mathrm{~kJ} / \mathrm{mol}, \Delta H_{\mathrm{L}}=$ $493.7 \pm 16.7 \mathrm{~kJ} / \mathrm{mol}, T_{\mathrm{mS}}=339.8 \pm 1.4 \mathrm{~K}$ and $T_{\mathrm{mL}}=$ $344.3 \pm 1.3 \mathrm{~K}$ - are in good agreement with both the calorimetric and intrinsic fluorescence results.

The experimental parameters characterising the denaturation of cardosin A can be used to calculate the free energy change for denaturation at any temperature, $\Delta G^{\circ}(T)$, using the modified Gibbs-Helmholtz equation

$$
\begin{aligned}
\Delta G^{\circ}(T)= & \Delta H\left(T_{\mathrm{m}}\right)\left(1-\frac{T}{T_{\mathrm{m}}}\right) \\
& +\Delta C_{p}\left[\left(T-T_{\mathrm{m}}\right)-T \ln \left(\frac{T}{T_{\mathrm{m}}}\right)\right]
\end{aligned}
$$

and the temperature where $\Delta G^{\circ}(T)$ reaches a maximum, $T_{\mathrm{s}}$, using

$T_{\mathrm{s}}=T_{\mathrm{m}} \exp \left[-\frac{\Delta H\left(T_{\mathrm{m}}\right)}{T_{\mathrm{m}} \Delta C_{p}}\right]$

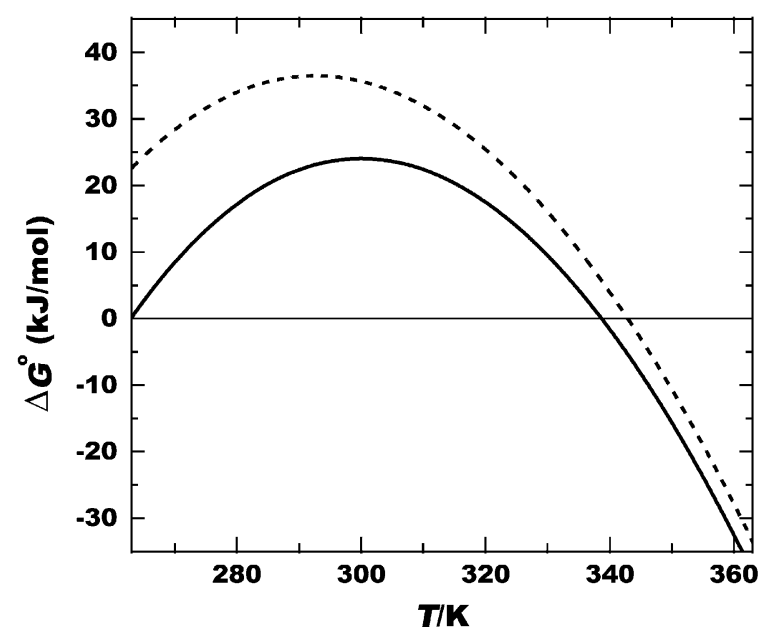

Fig. 8. Temperature-dependence of the Gibbs energy for the short chain (solid line) and the long chain (dashed line) of cardosin A at $\mathrm{pH}=5.0$ plotted according to Eq. (2).
[33]. The protein stability curves for both cardosin A chains calculated with these equations and the experimental parameters obtained in this work are shown in Fig. 8. The values of $T_{\mathrm{s}}, \Delta G^{\circ}$ at $T_{\mathrm{s}}$ and at $298 \mathrm{~K}$ are given in Table 1 . The calculated values of $T_{\mathrm{S}}$ testify to the relative hydrophobity of cardosin A, assuming that this enzyme can, in principle, be cold-denatured [34]. The stability of cardosin A chains at $298 \mathrm{~K}$ is $21-38 \mathrm{~kJ} / \mathrm{mol}$. This seems to be reasonable because it is known that in biological processes energy is exchanged, as rule, by portions of $17-34 \mathrm{~kJ} / \mathrm{mol}$ [22]. Thus, to make protein degradation feasible or to provide an elevated degree of protein flexibility, which is essential for its function, the upper limit of the protein conformational stability should have the same value.

\section{Acknowledgements}

DGP, CSO and ACS are fellowship holders from the Fundação para a Ciência e a Tecnologia, Portugal (Refs. SFRH/BD/1067/2000, PRAXIS/P/QUI/10131/ 98, and PRAXIS/BD/11019/97, respectively). We thank Dr. H. Guerra Fernández for generous access to his experimental facilities and help in carrying out isoelectrofocusing experiments, and NSD Skinner for proof-reading.

\section{References}

[1] V. Vetvicka, J. Vetvickova, I. Hilgert, Z. Voburka, M. Fusek, Int. J. Cancer 73 (1997) 403.

[2] V. Vetvicka, J. Vetvickova, M. Fusek, Cancer Lett. 129 (1998) 55.

[3] X. Lin, G. Koelsch, S. Wu, D. Downs, A. Dashti, J. Tang, Proc. Natl. Acad. Sci. USA 97 (2000) 1456.

[4] R.I. Brinkworth, P. Prociv, A. Loukas, P.J. Brindley, J. Biol. Chem. 276 (2001) 38844.

[5] J.B. Dame, G.R. Reddy, C.A. Yowell, B.M. Dunn, J. Kay, C. Berry, Mol. Biochem. Parasitol. 64 (1994) 177.

[6] M. Monod, G. Togni, B. Hube, D. Sanglard, Mol. Microbiol. 13 (1994) 357.

[7] C. Craig, E. Race, J. Sheldon, L. Whittaker, S. Gilbert, A. Moffatt, J. Rose, S. Dissanayeke, G.W. Chirn, I.B. Duncan, N. Cammack, AIDS 12 (1998) 1611.

[8] M. Ramalho-Santos, J. Pissarra, P. Verissimo, S. Pereira, R. Salema, E. Pires, C.J. Faro, Planta 203 (1997) 204.

[9] M. Ramalho-Santos, P. Verissimo, L. Cortes, B. Samyn, J. Van Beeumen, E. Pires, C. Faro, Eur. J. Biochem. 255 (1998) 133. 
[10] C. Frazao, I. Bento, J. Costa, C.M. Soares, P. Verissimo, C. Faro, E. Pires, J. Cooper, M.A. Carrondo, J. Biol. Chem. 274 (1999) 27694.

[11] D.R. Davies, Annu. Rev. Biophys. Biophys. Chem. 19 (1990) 189.

[12] J. Costa, D.A. Ashford, M. Nimtz, I. Bento, C. Frazao, C.L. Esteves, C.J. Faro, J. Kervinen, E. Pires, P. Verissimo, A. Wlodawer, M.A. Carrondo, Eur. J. Biochem. 243 (1997) 695.

[13] P. Verissimo, C. Faro, A.J. Moir, Y. Lin, J. Tang, E. Pires, Eur. J. Biochem. 235 (1996) 762.

[14] G. Fairbanks, T.L. Steck, D.F. Wallach, Biochemistry 10 (1971) 2606.

[15] C.R. Merril, D. Goldman, S.A. Sedman, M.H. Ebert, Science 211 (1981) 1437.

[16] A.C. Sarmento, Ph.D. Thesis, Aveiro University, Portugal, 2002.

[17] A. Ruiz-Arribas, R.I. Santamaria, G.G. Zhadan, E. Villar, V.L. Shnyrov, Biochemistry 33 (1994) 13787.

[18] E.A. Burstein, N.S. Vedenkina, M.N. Ivkova, Photochem. Photobiol. 18 (1973) 263.

[19] E.A. Burstein, Mol. Biol. (Moscow) 17 (1983) 455.

[20] Y.K. Reshetnyak, E.A. Burstein, Biophys. J. 81 (2001) 1710.

[21] N. Sreerama, S.Y. Venyaminov, R.W. Woody, Protein Sci. 8 (1999) 370.
[22] P.L. Privalov, Adv. Protein Chem. 33 (1979) 167.

[23] J. Gomez, V.J. Hilser, D. Xie, E. Freire, Proteins 22 (1995) 404.

[24] L.N. Lin, A.B. Mason, R.C. Woodworth, J.F. Brandts, Biochemistry 33 (1994) 1881.

[25] A. Ruiz-Arribas, G.G. Zhadan, V.P. Kutyshenko, R.I. Santamaria, M. Cortijo, E. Villar, J.M. Fernandez-Abalos, J.J. Calvete, V.L. Shnyrov, Eur. J. Biochem. 253 (1998) 462.

[26] D.E. Kamen, Y. Griko, R.W. Woody, Biochemistry 39 (2000) 15932.

[27] H. Fukada, J.M. Sturtevant, F.A. Quiocho, J. Biol. Chem. 258 (1983) 13193

[28] V. Edge, N.M. Allewell, J.M. Sturtevant, Biochemistry 24 (1985) 5899.

[29] K. Takahashi, J.M. Sturtevant, Biochemistry 20 (1981) 6185.

[30] S.P. Manly, K.S. Matthews, J.M. Sturtevant, Biochemistry 24 (1985) 3842.

[31] M. Munson, S. Balasubramanian, K.G. Fleming, A.D. Nagi, R. O’Brian, J.M. Sturtevant, L. Regan, Protein Sci. 5 (1996) 1584.

[32] P.L. Privalov, N.N. Khechinashvili, J. Mol. Biol. 86 (1974) 665.

[33] W.J. Becktel, J.A. Schellman, Biopolymers 26 (1987) 1859.

[34] P.L. Privalov, Crit. Rev. Biochem. Mol. Biol. 25 (1990) 281. 